\title{
Boerhaave Syndrome
}

Michael T. Vest, DO; Peter Dross, MD

From the Department of Medicine at the Christiana

Care Health System in Newark, Delaware, and the

Sidney Kimmel Medical

College at Philadelphia

University and Thomas

Jefferson University in

Pennsylvania (Dr Vest) and the

Department of Radiology at Christiana Care Health System

in Newark, Delaware (Dr

Dross)

Financial Disclosures:

None reported.

Support: None reported.

Address correspondence to

Michael T. Vest, DO

Christiana Care Health

System, 4745 Ogletown-

Stanton Rd, Newark, DE

19713-8002.

Email: mvest@christianacare.

org

Submitted

April 4, 2017;

revision received

April 22, 2017;

accepted April 26, 2017.

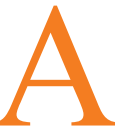

n 86-year-old man with a history of dementia presented to an emergency department with 2 weeks of worsening nausea and vomiting. His vomiting became "violent" and was associated with chest pain and shortness of breath 1 hour before presentation. A computed tomographic (CT) scan of his chest showed pneumomediastinum (image $\mathbf{A}$, arrow). He was endotracheally intubated and treated with a fentanyl infusion titrated to comfort, piperacillin/tazobactam, and intravenous fluids. A watersoluble contrast swallow study obtained by repositioning his orogastric tube into his esophagus demonstrated contrast extravasation from the distal esophagus into the mediastinum consistent with a perforation (image B, arrow). Because of concerns about quality of life if he were to survive this critical illness, surgical repair was not done. The patient was extubated and provided with comfort care and died soon after presentation.

Boerhaave syndrome (spontaneous rupture of the esophagus) often requires surgical intervention, and delay in diagnosis is associated with worse outcomes. ${ }^{1}$ Vomiting and chest pain are classic symptoms, and subcutaneous emphysema may be noted on examination. ${ }^{2}$ Findings on CT

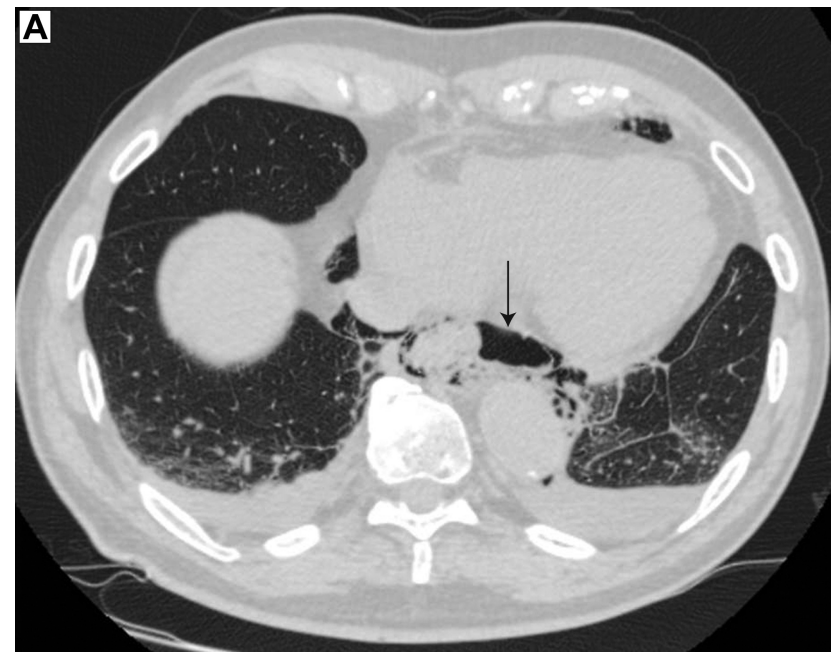

scan can be suggestive; however, a swallow study is essential to identify the site of perforation. (doi:10.7556/jaoa.2018.165)

\section{References}

1. Lindenmann J, Matzi V, Neuboeck N, et al. Management of esophageal perforation in 120 consecutive patients: clinical impact of a structured treatment algorithm. J Gastrointest Surg. 2013;17(6):1036-1043. doi:10.1007/s11605-012-2070-8

2. $\mathrm{He} \mathrm{X}, \mathrm{He} \mathrm{Z}, \mathrm{Li} \mathrm{H}$. Boerhaave syndrome: challenges in diagnosis and treatment of the early presentation and its complication. J Trauma Acute Care Surg. 2018;84(6):1030-1032. doi:10.1097/ TA.0000000000001830

(๖) 2018 American Osteopathic Association

Keywords: boerhaave syndrome, esophagus, critical care

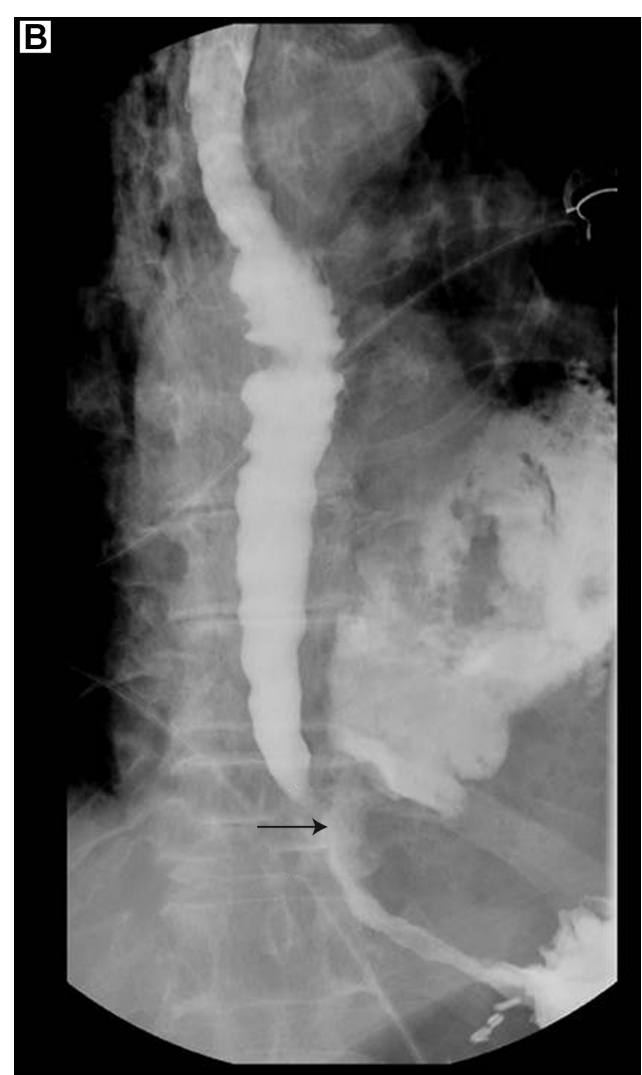

